Potsdam, as a consequence of differential erosion, rise the ranges of the Baraboo bluffs, which also are probably monadnocks reaching a considerable height above the baseleveled plain of central Wisconsin. As to the extent of territory over which this central Wisconsin plain may be traced, I can say nothing, but I anticipate that the area will be found to be large.

While accurate measurements were not made, the plain in the crystalline rocks apparently has a southern slope. From numerous aneroid measurements from the railroad, near Wausau, by Messrs. Buckley and Weidman, the dissected plateau both east and west of the Wisconsin River rises at many places to a uniform elevation of about 1,400 feet. At the Wausau bridge the river is about 1,180 feet above the level of the sea. In order to reach the baseleveled plain, one must therefore climb to a height of about 320 feet above the river. At Mosinee the river is about 1,100 feet above the level of the sea, and here the plain is estimated to be 200 feet above the river level. This gives a southern slope to this plain between Wausau and Mosinee, a distance north and south of about 12 miles, amounting to at least 100 feet.

On the geological map of Wisconsin* it will be seen that the Paleozoic formations about the pre-Cambrian core of central Wisconsin constitute a very gently southward plunging anticline. How far erosion had gone toward a baselevel in the crystalline area before Cambrian time is undetermined, but the uniform fashion in which the streams cut the Potsdam and strike the crystallines at about the same level for considerable distances away from the main Archean area indicates that if not baseleveled at the time of the Cambrian transgression, the area approached a peneplain.

As to the age of the central Wisconsin baseleveling no more than conjectures can at

$$
\text { * L. c., Pl. I. }
$$

present be given. One naturally connects it with the Cretaceous transgression, which extended very far over the Upper Mississippi valley, and perhaps over all of it.

As to the agent or agents which accomplished the baseleveling, no evidence was obtained, but because calculations show that running water is far more potent as a denuding agent than the ocean, I incline to the belief that the major part of the work was done by rivers, although it is possible that as a result of the transgression of the ocean some of the final work may have been that of marine denudation.

Observations upon which the above article is based were made by me while on a trip with some of the advanced students of the University of Wisconsin, the primary purpose of the trip being to study the crystalline formations of central Wisconsin. It is hoped at a future time to take accurate measurements of the heights of the river terraces and of the baselevel at various points, in order to give a more exact account of them.

C. R. VAN Hise.

\section{DECIMAL NUMERATION IN THE UNITED STATES.}

Mr. Herbert Spencer's arguments against the adoption of the metric system, republished in the June number of $A p$ pleton's Popular Science Monthly, are chiefly based upon the idea that the division of measures into tenths is so inconvenient that men ' under the pressure of business needs' tend to abandon the decimal system in favor of the duodecimal. Whatever may be the case in England, it is evident that in the United States the tendency is quite the opposite, and that we are gradually bringing the divisions of our weights and measures into accord with our notation. This evolution is not being accomplished by ' $\mathrm{Bu}$ reaucratic Coercion,' but by the free action of natural forces, the beneficient results of 
which process we have learned from Mr. Spencer to expect with such confidence.

We may first note the prevailing tendency in the division of units of length. In land surveying, where a change of the mode of measurement causes more inconvenience than elsewhere, the advantages of the decimal division are so strongly felt that hundreds of feet and tenths of a mile and a foot are being used to a considerable extent instead of rods and inches. This is true, $I$ think, to a greater degree in the West than in the East. Even in common speech it is more usual to estimate a distance as, say, sixty feet or two hundred feet, than in yards or rods. The division of the foot into tenths has come into use in spite of the inconvenience of a unit so nearly like the inch, yet so difficult to reduce to it. The subdivision of the inch into twelfths originally in vogue is almost unused, while tenths of an inch are superseding not only the line, but also the fractions, of quarter, eighth and sixteenth. Fine measurements are more often expressed in hundredths of an inch, and even where the old terms are used in speech they are often written .50 or .125. This change has been made not by scientists, but by machinists and practical men, who have most occasion to use such measurements.

In weights the same evolution toward the decimal system is noticeable. The ton of 2000 pounds, because it is capable of decimal division, has almost entirely driven out the ton of 2240 pounds. A Western man does not know of the existence of the 'long ton' except from his arithmetic. The bushel has become in common practice a unit of weight and, being a useless incumbrance, is being displaced by the hundred weight. Measurements of grain and vegetables are taken in pounds and hundreds of pounds, and then, if necessary, reduced to bushels.

Units of volume apparently have not been subjected to decimal division, but it is more customary to speak of ten, one hundred or five hundred quarts or gallons than it is to use other multiples, and receptacles are made to correspond with this custom. In the measurement of area the same is true. Our city streets, blocks and lots are measured in multiples of ten more often than of any other number.

In the measurement of time, where the laws, not of Nature, but of the Chaldeans, have prevented the use of decimal division, the existing duodecimal division is almost ignored. The division of the hour into balves, quarters and thirds, which appears to Mr. Spencer such a great advantage, is entirely disregarded by railroad men and o a large extent by everybody. 'Ten thirty' and 'nine forty-five' are rapidly superseding the expressions 'half past ten' and ' a quarter before ten.' We even write 5:25 and 9:41.5 as though it were in decimal notation. As for the third of an hour I never heard of its use either in speech or practice. Days are coming to be used in multiples of ten both in business and in ordinary life. We go for a ten-days' trip or give our notes for one hundred days instead of using weeks or months.

In arithmetical operations decimals are being used more and more in the place of vulgar fractions. This is a commercial age and country, and 'the business man' thinks in per cents. He says his health is fifty per cent. better than the day before and he discounts the newspaper twenty-five per cent. Notwithstanding the statement of Sir Frederick Bramwell that the decimal system is absolutely incompatible with mental arithmetic, the ordinary man persists in using it, and if vulgar fractions are given him to add or subtract he will change them over to decimals before performing the operation and the result back again rather than use them. In some of our best schools children are taught the use of deci- 
mals before common fractions, as they are virtually familiar with decimals when they have learned their notation, and the transition to fractions of other denominations than ten is more easy than the reverse. In common life we are discarding vulgar fractions, except the simplest, and using decimals,

The increasing use of multiples of ten in place of the dozen and gross is another indication of the same disposition to gravitate toward a decimal system. Vegetables are now often sold in bunches of tens and fives, and many small articles of dry goods are put up in the same way. As this makes the pricing of the articles so much simpler it seems likely to prevail.

Judging from present progress in the United States, 'the pressure of business' and the necessity of simplification is forcing the American people to a decimal division of weights and measures. People will use tenths in practice whether the government favors it or not. The only question is whether the units will be those of all the world except England or a separate system. If the metric system is not adopted it will not be long before we shall be using mostly tenths and hundreds of pounds, feet and inches. While this would be better than the present chaos, it would not be so good as the metric system in which all the units are in simple relations to one another.

As for the objections raised against the metric system on the ground of inconvenience, we know by experience with our decimal coinage how groundless they are. The most ignorant among us have no practical difficulty with those divisions which appear so unnatural to the English. Mr. Spencer objects to the metric system on the ground that ten is not divisible by three, and thinks the present customs preferable on account of 'the widow's thirds and in Parliamentary Acts the two-thirds majority.' The illustrations are unhappily chosen; since the
English pound is no better divisible by three into shillings than the American dollar into cents, and it is hard to see how the adoption of a duodecimal system would insure the division into thirds of a Parliament consisting of a varying number of men. The question is often asked what is a shopkeeper to do when a customer wants a third of a kilogram. If such a case should occur the shopkeeper need only pile 2 's' and 1's of each denomination on his scalepan until the weight was reached within the limits of delicacy of his scales. But what is he to do if asked for the third of a pound?. If " calculation in our present system is as easy as claimed, he would instantly perceive that he could get the weight by laying on the scalepan five ounces, five drams, nine and eleven ninetysixths grains. This also is a 'makeshift third.'

The objection is also urged that the metric system would not be in accordance with our division of time. But since the natural units of time, the day, the month and the year are incommensurable no system of numeration can agree with them. As it is, our notation and our measures of weight, length, area, volume and time have no relation to each other. With the adoption of the metric system our notation and all our measures except time will agree. The value of the Centigrade thermometer need not be discussed, since it is not a part of the metric system, and the adoption of that system does not carry with it the Centigrade thermometer. As there is no relation between the boiling and freezing points of water at an arbitrary atmospheric pressure and any system of weights and measures, the Fahrenheit scale is just as well suited to the metric system as any other. It should be noticed, however, that in both scales the fractions of a degree are reported in tenths, not in halves quarters and thirds. A thermometer scale 
might be devised, based on absolute zero, which would be really decimal, have no minus readings and be in accordance with the metric system.

It is unfortunate, theoretically, at least, that the meter is not exactly. a ten-millionth of the earth's quadrant. But the question with us in America is, shall we adopt as a unit the platinum-iridium bar in Paris, accurate copies of which are in all the national archives and the length of which is known in terms of the wave-length of light, or shall we continue to use as our unit a broken brass rod riveted in the middle which differs from everything else in creation.

Compound numbers, which to the French are known in ancient history, are to us a daily nuisance. They take up a good third of our arithmetics, by far the hardest third at that, and require about a year of a child's school life to learn even passably. If the 'English accountant' can add guineas, pounds, shillings, pence and farthings as rapidly as an American accountant can add dollars and cents, it must be because the greater difficulty of his task has caused a greater mental development. If Sir Frederick Bramwell can calculate by mental arithmetic how many grains of water there are in a gallon as quickly as a child can tell how many grams there are in a liter he is indeed a mathematician.

The requirements of scientific work are not so different from those of commerce as has been imagined. It is not a matter of indifference to the scientist whether his measures are capable of easy division. A chemist has to make more divisions into aliquot parts than a shopkeeper, as I know by personal experience in both capacities.

It is probable that the duodecimal notation would be preferable to the decimal, though it is not certain that it is the best that could be devised. Notations based on eight, sixteen and two have, I believe, been more favored by mathematicians than that based on twelve. The difficulties of a change are, however, almost inconceivable, perhaps as great as a change to a more perfect language would be, and it seems hardly worth while to take into consideration its possibility. The fact is that for the period intervening between that geological epoch when our saurian ancestor lost his sixth digit, to that perhaps equally remote date when men shall become intelligent enough to choose a better system of notation than the present, the world is doomed to a decimal system. Let us then make the best of it by bringing weights and measures in accordance with it and, instead of complaining, rather be thankful that the first human arithmetician had five fingers instead of seven, since he did not have the happy medium. It seems that the English, in spite of their national genius for devising incommensurable units, are moving as fast in the matter of adopting a better system of weights and measures as the Americans, and we may put faith even in the prophecy made by Matthew Arnold in one of his optimistic moods, that the time will yet come in England when the fact that an institution is an anomaly will be regarded as an objection, not an advantage.

UNIVERSITY OF WYOMING.

$$
\text { E. E. Slosson. }
$$

\section{THE USE OF THE HAIR HYGROMETER.}

For some time past there has been an increasing demand for a direct reading hygrometer, so constructed that it would indicate the relative humidity of the air with reasonable accuracy.

Among those hygrometers which have been considered as possibly suitable for this purpose is the Saussure's or hair hygrometer. Although formerly this hygrometer was looked upon merely as a. hygroscope, and was supposed to give only the approximate hygrometric state of the air, 